International Journal of

Supply Chain and Logistics

(IJSCL)

MANAGERIAL CHALLENGES IN USING LEANTECHNIQUUES IN DESIGNING A COMPREHENSIVE CHARACTERIZATION OF ORGANIZATION LOGISTICS AND PHYSICAL DISTRIBUTION SYSTEM: A CASE OF DEPARTMENT OF FIELD SUPPORT (DFS), UNITED NATIONS

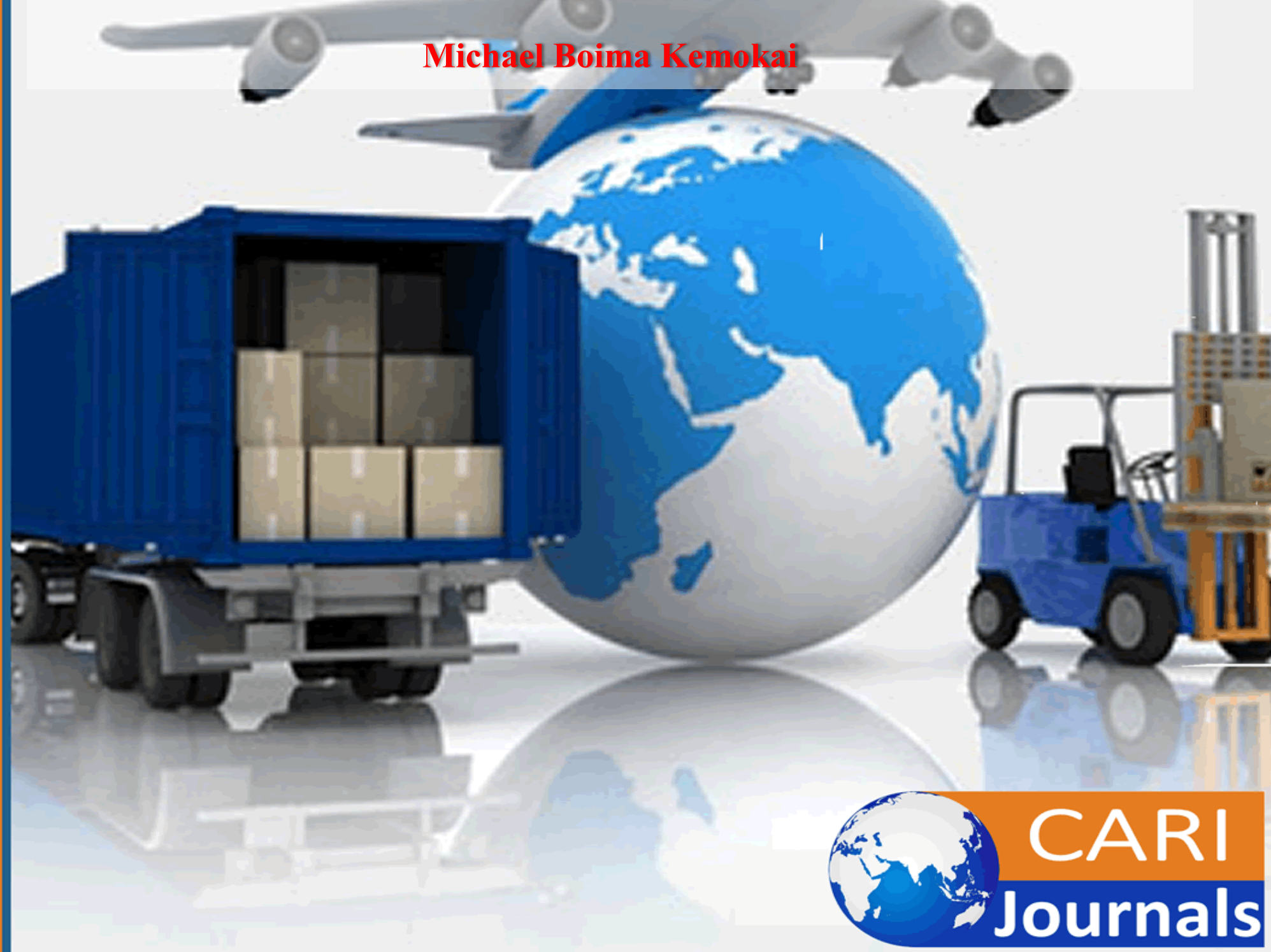




\title{
MANAGERIAL CHALLENGES IN USING LEAN TECHNIQUES IN DESIGNING A COMPREHENSIVE CHARACTERIZATION OF ORGANIZATION LOGISTICS AND PHYSICAL DISTRIBUTION SYSTEM: A CASE OF DEPARTMENT OF FIELD SUPPORT (DFS), UNITED NATIONS
}

\author{
${ }^{1 *}$ Michael Boima Kemokai \\ ${ }^{1}$ Post Graduate Student: The University of Liverpool \\ *Corresponding Author's E-mail: kemokai@un.org
}

\begin{abstract}
Purpose: The purpose of this study was to identify the managerial challenges in using lean techniques in designing a comprehensive characterization of the organization logistics and physical distribution system. The study further sought to determine the extent to which these challenges impact the logistics and physical distribution of goods and informed managerial practices.

Methodology: The study employed a qualitative research design. The study targeted all the senior managers at Director Levels at the GSC and the RSC and all the senior operational staff from supply chain and service delivery pillars in three (03) large Field Missions. These field missions are namely United Nations Stabilization Mission in Congo (MONUSCO); United Nations Mission in South Sudan (UNMISS); and the United Nations Support Office for AMISOM (UNSOA). This study used purposive sampling technique. The researcher purposively sampled fifteen (15) personnel; with three (03) participants each from the GSC, RSC, and three (03) participants each from the three (03) Field Mission. Primary data was obtained from the original sources using questionnaires and interview.

Findings: The results revealed that DFS did face various challenges in the implementation of lean strategies and that the operational difficulties experienced within its operations across field missions resulted in reduced customer satisfaction, increased supplier lead time and increased operational costs. The respondents indicated that they experienced a lack of understanding of the complexity of supply chain at the senior leadership level whereby most initiatives are tainted with personal agenda as a consequent the biggest hurdle to overcome is gaining enthusiasm and trust of the staff. They also indicated that there is a high risk of asset waste and loss due to assets remaining in stock for over one year without use. Further, they indicated that there are weaknesses in the management of construction or "self-constructed" projects; and weaknesses in the restructuring of the department of peacekeeping operations.
\end{abstract}

Unique contribution to theory, practice and policy: The study recommends that DFS should foster a continuous performance improvement mindset among staffs through planning, doing, checking and taking corrective actions on a balanced scorecard that integrates and aligns staff motivation and interest to the objectives of the organization. Also, objective and fair work plan 
and performance management are an ingredient to foster continuous improvement.

Key words: managerial challenges, lean techniques, characterization, logistics and physical distribution system, Department of Field Support

\subsection{INTRODUCTION}

Schweikhart and Dembe (2009) point to lean strategies as perhaps the most widely used management tools that organizations deploy when attempting to improve their business process efficiency and service quality. Lean concepts are a critical driving force that is gain from practices and can bring synergy to a work environment. The concept had tended to create a highquality system that drives continuous performance improvement (CPI) within an organization. Evidence from organization CPI had resulted in the fulfillment of multiple demands made by customers at their required pace (Shah \& Ward, 2003).

Lean strategies are considered a global standard for measuring the value added to client services. To ensure an organizational-wide success in any quality improvement project, Brun (2011) suggested that ownership of the quality improvement process most have a sponsor and an enormous commitment on the part of the organization to invest heavily in the training of personnel so that their performance meets the organization's expectations. In addition to the training requirements, there must be an explicit staffing requirement for any project and a welldefined standard for measuring staff performance. Evidence from past research revealed that organizations that applied lean techniques have generated an improved operational performance, achieving a high level of efficiency in product and service outputs. Their evidence, reinforced by Droste (2007) research findings, pointed to a cluster around lean strategies. These strategies include the following: the long-term thinking of the organization as it works to transform its business processes; the elimination waste program of an organization; the elements of mutual respect between partners in the organization's change collision; factors that generate organization's internal operational challenges, and the firm's normal growth; which are emphasized by the need for continuous performance improvement through learning by employees and the organizations. Lean strategies are used today in building organization culture in the United Nations Department of Field Support (DFS). It has become the core organization initiatives for improving the way it conducts business (UN, 2013).

The implementation of the Global Field Support Strategy (GFSS) was for improving the Department for Field Services (DFS) business process efficiency and the delivery of services (UN, 2013). However, the DFS business processes, in particular processes linked to the organization logistics and physical distribution processes have not been without challenges especially in the implementation of mandates of peacekeeping operations. These challenges included; difficulties in selecting appropriate logistics concepts given the organization resource constraints. By adapting the GFSS, the strategy provided a lean approach that could efficiently address these challenges linked to the logistics strategies of the DFS (UN, 2015). From a logistics and physical distribution perspectives, the concept might be considered a very expensive proposition that results in increases in the cost of holding inventory and rental of storage space. However, when considered, the concept of the UNSC share cost functionality, the merger-in-transit distribution could be seen as conventional and perhaps, less expensive (UN, 2015). Hence, with the notion of share cost functionality, the UNSC has the potential to widen their abilities to provide goods from an increased stock that they can hold and their ability to 
move physically these stock using third parties movers or through the Transport Movement and Integrated Coordination Center (TMICC) so that they can meet the requirements of Field Missions just-in-time (UN, 2015).

\subsection{Statement of the Problem}

A resolution (61/256) adopted by the United Nations on March 15, 2007, had set into motion actions that would strengthen the capacity of the DFS to manage the business processes of peacekeeping operations. In 2010, the DFS launched a comprehensive initiative in a strategic framework referred to as the Global Field Support Strategy (GFSS). The GFSS concept was a radical departure from wasteful DFS legacy operations (UN, 2013). The legacy systems had offered poor service quality and no added value to Field Missions operations (UN, 2010). This poor service quality was identified as a key challenge that the organization needed to tackle.

The earlier applications of the GFSS were focused primarily on establishing programs and infrastructure geared towards enhancing a culture of continuous performance improvement (CPI). The focus had been on the organization decision to improve and re-engineer the entire DFS logistics and physical distribution processes. Arguably, lean techniques were the cornerstone for much of the changes in the DFS logistics and physical distribution processes (UN, 2013). Lean techniques were used to identify CPI opportunities through methods that capture business processes and service delivery improvements (Shah \& Ward, 2003). This study sought to find out the managerial challenges in using lean techniques in designing a comprehensive characterization of the organization logistics and physical distribution system as the DFS implement the GFSS.

\subsection{Research Objectives}

i. Identify the managerial challenges in using lean techniques in designing a comprehensive characterization of the organization logistics and physical distribution system.

ii. Determine the extent to which these challenges impact the logistics and physical distribution of goods and informed managerial practices.

\subsection{LITERATURE REVIEW}

\subsection{Theoretical Review}

\subsubsection{Supply Chain Operations Reference (SCOR) Model}

The Supply Chain Operations Reference (SCOR) model is a supply chain management (SCM) grassroots initiative that usually applies to managing information flow as well as in products modeling. The SCOR model is an abstraction at the highest levels of the supply chain. When applying the model to a particular process in firms, they are linked to Levels - either at Level 3 or the lowest layers of the implementation phase (SCOR, 2007). Findings from the application of the SCOR initiative highlights an important feature of the model. Suggestions from the findings tend explained that firms have accepted the model and had implemented it to gain a critical mass.

Huang, Sheoran and Wang (2004) findings had revealed that there were gains obtained from a realization of a de facto industry standard. The SCOR model is used in describing high-level business processes. These high-level business processes associated with the implementation phases of process changes are influenced by the objectives of gaining customer's demand satisfaction (SCC, 2000). The highest level attainable using the SCOR model is organized 
around four types of a business process. The processes include a planning stage, a sourcing stage, the making stage and finally, the delivering stage. These processes are a representation of the vertical neutral abstractions that are characterized by all demand/supply planning processes, all purchasing/procurement planning processes, all manufacturing/production planning processes, all order entry planning processes and all outbound logistics planning processes, as well as returning activities processes. What the model presents are tools that provide a framework from a perspective that is standard that can be described as as interdependence process. Huang, Sheoran, and Wang (2004) had argued that the approach were particularly useful in targeting the need for mapping an organization supply chain activities. It could also be applied to the varying and multiple industries=vertical complex activities that ran across the organization supply chain.

The SCOR model itself is a framework that is base on a hierarchy decomposes at Levels. At Level three (03) of the SCOR model, is the Process Element Level (PEL). The PEL defines activities that are generalized and apply to a variety of products or services. These activities are part of a flow of information that follows from analyzes, design, and implementation of an actual operational supply chain execution. The information flow also informs the organization planning processes and best-practices using enabling technology indexing/cataloging associated with the Process Elements. The information flow that informs the actual supply chain execution and planning processes are used as an implementation guide. Their use has allowed for the development of an organization business framework with a common language that facilitates horizontal processes that are integrated across different business units and players in the value chain. The SCOR model is a strategic tool that offers the firm,s benefits of standardization and has been using in describing, communicating, measuring, controlling and fine-tuning the complex processes of the firm's SCM. The benefits are the outcomes of the supply chain partnerships associated with the organization's value chain model that follows from the implementation and adherence to the framework of the SCOR model (SCOR, 2007).

\subsubsection{Process Theory}

The application of process theory on organization's performance has tended to suggest an improvement in business process efficiency. Process theory, have been used to identify operations that can be individually and closely examine so that a process map is developed. A process map is used for providing an understanding of essential characteristics of operations and is used to generate useful detailed information for carrying out information analysis (Aldowaisan \& Gaafar, 1999; Bisson \& Folk, 2000; Keller \& Jacka, 1999). From the analysis, it should enable the design of a process flow that would help improve business operations.

Processes that drives critical business operations should be the most efficient way of managing an organization at all levels. Eventually, the process should support the overall goals of the organization. Observations on the current changes in UNSOA where processes are now used to informed the organization structure tends to support its overall objectives. UNSOA current path aimed at improving processes should equally translate into an improvement in the internal efficiencies, as well as its effectiveness, adaptability and the levels of customer services. What this would imply is that if UNSOA documents it process map and eliminate wasteful or nonvalue activities, this should provide insight that can help improve operations. A similar argument that fits with the observation for UNSOA can be found in the research work of Damelio (1996); and Sealander and Cross (1999). They had argued that by documenting processes, it can lead to insights into the changes that can assist in improving business organization operations (Damelio, 
1996; Sealander \& Cross, 1999). This theory informs this study since the DFS is involved in logistics and physical distribution operations. The theory outlines how operations are enhanced by using the right processes.

\subsubsection{Critical Management Theory}

Critical management theory is functional and is considered critical towards the institutionalization of social and intellectual practices. The elements that characterize these practices include profits that are imperative for businesses, inequality along racial lines or irresponsible environmental practices. The findings from Alvesson et al. (2009), had sought to explain the common challenges which relate to the domination of capitalist free market economy with an anticipation of a development of an alternative. The findings are useful for the research on the DFS operations. For instance, recent activities at UNMISS in adopting concepts of supply chain and service delivery seeks an alternative to its past operations. UNMISS had a look towards the idea of lean philosophy as a means of re-engineering its operations, but with deep skepticisms. The observation on UNMISS can be supported using the findings from Adler et al. (2007). They had put it succinctly, that there are core elements that can be considered common to all organizations. These basic elements presented a deep skepticism regarding the moral defensibility of social and ecological sustainability that are prevailing concepts of forms of management. UNMISS current operational improvement programs are faced challenges of defensibility and sustainability. Despite the adoption of processes that would allow for improvement, there are strong signs of an increase marginal effect on UNMISS operations. MONUSCO, on the other hand, have not gone far in the implementation of the GFSS but faces resistance to change (UN, 2013).

Critical management theory can contribute to the re-engineering of the DFS operations. The idea that managers should be engaged rather than criticize provides the basis for having counterbalancing factors for any obstacles in implementing a program of performance improvements. Apart from the argument for managerial competencies, the success of the DFS operations depends heavily on counterbalancing factors such as external policies of the various member countries of the United Nations.

\subsection{Empirical Review}

One of the many initiatives that globally organizations use to improve their performance is lean philosophy. Organizations around the world have adopted lean philosophy to improve performances and to date, the strategy remains efficient in the face of increasing demand from customers for an improved quality of products and services business organization provide (Schonbergerm, 2007). The critical aspects of any strategies that are considered lean are the streamlining and creation of a system that is highly efficient. The system must be designed to produce outputs that match the pace of the demand from customers while ensuring the elimination any form of waste (Shah \& Ward, 2003). The elimination of waste is the core thrust of lean strategies. The principles involve eliminating waste. The waste includes waste in time, materials, efficiency, personnel, or processes to a range of non-value-added activities. The later include rework, scrap, excess inventory, excess processing, delays and transporting (McManus, 2007).

According to Jusko (2007), lean strategies are considered a cooperative process for business survival and success. He went on to suggest that if a business organization most experience 
growth and continuously improved, they had implemented strategies that were based on lean concepts. Organizations that implemented lean concepts were also required to adopt a continuous performance improvement work culture with a bias for action (Danford, 2007). Accordingly, Edgeman and Bigio (2004) suggested that lean concepts can be applied to all elements of an organization's processes or workflows. They cited factors that included organizational support that fostered the development of service quality in the areas of human resource management, financial management, procurement, and physical distribution. Their findings exposed problems associated that are associated with the traditional organization. The Food and Agriculture Organization (FAO, 2007), for instance, found its own research, that duplications, and the lack of appropriate and timely communication between organizations and their clients, were observed to be running rampant in traditional organizations that had not adopted lean concepts. The FAO also found that institutions that had implemented lean concepts were proactive and had the potential to plan effectively for the unforeseeable. They had the ability to reinforcing decisionmaking mechanism that allowed for the positioning of all resources which would facilitate quick responses (FAO, 2007). In this way, if there were a downturn in demand, the organization would be able to address any disruption without layoffs or significant productivity losses (Mentzer, 2001).

Organizations that have adopted lean principles have seen amazing results in areas of cost effectiveness, inventory reduction, improved quality of product and an increased customer satisfaction (Ketchen \& Hult, 2006). Lean experts believe that when lean tools are properly applied, there can be a dramatic improvement in the organization performance and financial position (Kouvelis, Chambers, \& Wang, 2006). Lean thinking primarily focuses on eliminating waste that is costing a tremendous amount of time and money. These wasted time and money are said to have a serious effect on the ability of any organization to improve its performance globally through a smooth and efficient flow (Larson \& Halldorsson, 2004).

According to the findings of Movahedi, Lavassani and Kumar (2009), there are benefits from lean transformation if organization adopts the right strategy. Their evidence suggested that business organizations who adopt lean philosophy for the purpose improving their performance, gain a boost of $35 \%$ in annual productivity in that, their on-time delivery increase by a near $100 \%$, while floor space reduces by up to $75 \%$. There is also evidence to suggest that cut in defects by $20 \%$ annually. Businesses also experience a slash in inventory by more than $75 \%$, with an improvement in the quality of up to $85 \%$. There are other benefits that the firms gain from information. They include reduce costs, increase capacity, increase customer and employee satisfaction for organizations that implemented lean strategies(Movahedi, Lavassani, \& Kumar, 2009).Their argument supports the idea put forward by Simchi-Levi, Kaminsky and Simchi-levi, (2007) that suggests that lean organizations have a full understanding of customer's value. They further suggested that lean concepts tend to focus on the main processes that serve to provide a platform for a business organization continuous performance improvement (CPI). The desired goals for lean business organizations are to ensure the provision of a perfect value for a customer through the creation of a suitable value process that eliminates waste or results in zero waste (Simchi-Levi, Kaminsky, \& Simchi-levi, 2007).

\subsubsection{Lean Strategies}

Business organizations that do more with less are refer to as a lean business organization. They use less of the following - human efforts, equipment, time, and space. Lean strategies are applied 
to business process transformation so that when less human efforts, less equipment, less time and less space come closer and closer, they can provide customers with what they exactly want, the time they want it, the place they want it and at what price they are willing to pay that item meets their cost/value expectations (Simchi-Lev \& Kaminsky, 2007). The narrative provided by Simchi-Lev and Kaminsky, (2007) are similar to GFSS new service delivery model. The model allows the DFS to leverage its economic of scale with a rapid response to diverse demands by exercising the highest quality standard and client satisfaction.

Some other challenges are linked to wrongly applying lean philosophy. Haag et al., (2006) cited the issues related to errors and scraps created from a typical production process that cut output in half. They also found job-related injuries and their undesirable side-effects that were due to a non-lean production process. New products time to market were usually half. What this meant is that there was a wide variety of products within product families that offered additional cost that was very modest. The capital investments required to implement the lean approach were slight, even negative. Cooper, Lambert, and Pagh, (2012) were able to find that organization was able to free up or sell facilities and equipment.

\subsubsection{The Five Principles of Lean Thinking}

Identification of customers and what they consider as value added to products or services are considered entry point. It is where firms recognize that there is a small portion of efforts and time that any organizations can put into a process of producing a product or service. The aim is to add value to the product or service that would, in turn, meet the satisfaction of the customer (Movahedi, Lavassani, \& Kumar, 2009). Providing a clear definition of value regarding particular products or services, drawn from the perspective of the end customer, will allow the organization to be able to identify and remove all the non-value activities. In this case, it could be seen from an entire set of activities where all parts in the organization value stream are involved in the joint delivery of products and services. The approach highlights a process that can be described as end-to-end, which provides value to the customer.

Danford (2007) found from his research on eliminating waste in any process that only 5\% contribute to activities that added value. He discovered that in the service environment there can be an increase in added value to the customer by 45\%. Judging from Danford (2007) findings, we can suggest that by eliminating waste, organizations can ensure that their products or services "flows" without any disruption, detour or longer waiting time, so that the goods or services are delivered in time to the end customer. He further suggested that by understanding the demanding customer for products or services produced by a firm, it should allow the organization to create processes that respond to these customer's needs. In this way, firms only get to manufacture what is wanted by clients and when the customer wants it (Movahedi, Lavassani, \& Kumar, 2009).

Movahedi, Lavassani, and Kumar (2009) were quick to highlight the significance of process improvement when creating a 'flow' and 'pull' system. In their findings, they were keen to stress that firms should start with radically re-engineering individual process steps when creating a 'flow' and 'pull' systems. They observed that there were gains from process re-engineering when the full steps significantly linked together. When this happens, they suggested the inevitability that more layers of waste would become visible. In this way, the firm improved processes will continue towards an end point that is theoretically perfect. When this stage is realized, the firm 
entire efforts and time would be directed at producing value-added products and services that resulted in creating customer satisfaction at the end stages (Kallrath \& Maindl, 2006). The launch of the GFSS in 2010 was the DFS decision to refuse to accept waste. What the DFS approach highlighted, suggests that lean strategies included a method for creating Lean Transformational Leadership (LTL). The strategies were geared towards continuous performance improvement (CPI) in the organization processes, allowing for significant benefits that included leadership commitments, employee autonomy, and a transparent organization (UN, 2009).

Wormack and Jones (2003) provided a prescription for eliminating waste from the introduction of five (05) stages. These steps are considered useful for analyzing the impact of lean on the DFS business process transformation so that it adopt a robust logistics and physical distribution system that deliver quality services and derived client satisfaction. Wormack and Jones (2003) five (05) stages lean strategies are primarily aimed at addressing waste eliminations. The five (05) stages process appears to be useful for establishing the gains and failures the DFS has experienced in implementing the GFSS, the UN comprehensive improvement initiatives. Their five (05) stages processes commence from waste elimination, also referred to in Japanese as muda. It is at this point that the organization can define client value regarding goods or services. In this context, a similar characteristic is observed from the DFS implementation of the GFSS across large and small Field Missions.

Waste eliminations continue to remain a serious challenge. At this stage of the lean process, the concept of continuous performance improvement (CPI) would have significantly struck a core with the business process efficiency and delivery service theme of the DFS and any organization implementing lean. For the second stage, they identified the chain value process that ends with the provision of services to the client. It takes into account the non-value added processes that can be reduced and eventually eliminated. The third stage of the process involved the creation of a flow. The flow is perhaps critical to the delivery of goods from the GSC and RSC to the Field Missions. Ultimately, the flow is the end state that delivers products and services to clients.

The re-engineering of the flow business processes in the DFS has allowed, for instance, a reduction in client waiting time, equipment idle time, and the processing time, with an ultimate end state of goods and services delivery to Field Mission. It is at this stage that we should be able to find any changes in the transforming the entire process of the organization. The fourth stages of the process, referred to as the pull process, allowed the client to demand goods or service in the business process. The method described were lacking at the DFS, until more recently. However, the culture is yet to take hold. However, the pull process could gain a significant hold if the acquisition planning processes in Missions such as MONUSCO, UNMISS, and UNSOA are considered critical in implementing lean. Whether this has translated into a significant reduction in waste and improves business process efficiency and service delivery and by what percentage, would be an important part of this investigation. The last stage, which this study will explore, is the stage of perfection regarding the levels of current lean successes through the adoption of the GFSS by the DFS (UN, 2009).

Fiume (2004) draws our attention to a lean success story when he discusses 'Lean at Wiremold.' The application of Lean at Wiremold witness a decade of 'Lean Thinking' in every aspect of the firm's operation. By leveraging key aspects of the business assets, notably people; Fiume (2004) described them as the willing worker. For him, the success of lean strategies had hinged on the organization making sure that structure, culture, job designs and policies were all geared toward 
making lean work. The DFS approach to lean implementation has similar characteristics. The DFS depends on the support from people. They are the organization senior leadership and operatives that had ensured that the concept was not just a tactic but a strategy. The GFSS concept had driven the organization culture of change so that people in the organization see lean strategies as the way of operating (UN, 2015). The environment that was being described by Fiume (2004) is similar to the situation at the DFS. The DFS, like Wiremold, see the implementation of lean strategies a way that can improve logistics and physical distribution operations in the delivery of services to Field Mission.

\subsubsection{Components of the Lean Operations}

Lean operations comprise various integrated elements that allow organizations to develop efficient and effective processes which create a lean organization in a modern context (Kallrath \& Maindl, 2006). Judging from the idea they had advanced about the lean organization, Kallrath and Maindl, (2006), pointed to the need for firms to understand and measure the extent to which these integrated elements linked to lean concepts, adds value to their business operations. If we consider their findings as contributing a business improvement in a modern context, we might want to consider the importance of lean agents in the implementation of lean concepts as part of a business process efficiency method. According to Lambert (2012), lean agents can easily adapt to improve process changes within the organization. For instance, consider a lean supplier; they could be single out from their pricing strategy, which is often lower due to the efficiencies of their lean processes and improvement in quality. As such, at any incoming inspection for improvement in quality at the next link of the improvement process, these firms would need as they are considered to deliver on time, and has an organizational culture that is characterized by continuous performance improvement (Jusko, 2007). By inferring from the findings of Jusko (2007), for the DFS to achieve lean operations, it has to develop and include lean suppliers, in the organization value stream as part of its overall supply chain management and service delivery systems. The DFS, in this context, should consider the need to encourage goods and service providers to make the lean transformation. To achieve this, the DFS would have to involve these suppliers in the DFS lean activities. Research findings from Halldorsson et al. (2007) suggested that if organizations can develop a partnership that drives their partners to make the lean transformation, both organizations would be able to help jointly fix problems and share savings. They added that such an approach could help suppliers achieved a set of continually declining price targets and increasing quality goals.

A procurement processes that is built on lean concepts are usually an automated procurement process or described as e-procurement. Procurement transactions that are conducted using electronic procurement system are strategic sourcing, and the use of applications that supports reverses auctioning, allow buyers involve in this electronic transaction to use applications that are web-based (Kallrath \& Maindl, 2006). Electronic procurement or e-Procurement is acquisition techniques that use software applications. The use of e-Procurement system usually results in the removal of the human elements which would normally be involved in multiple procurements that is associated with integrated financial solutions (Harland, 2012). A similar approach is described by the use of Umoja by the DFS. Umoja is a web base application that has harmonized most of the UN business processes (UN Peacekeeping: Documentation, 2007). The key to lean procurement is visibility. It is seen by the DFS use of the United Nations Global Marketplace (UNGM) which allows vendors to registered and see general and specific 
procurement notice, allowing them to participate in the UN procurement activities. Suppliers can "see" into the UN operations, and the UN can "see" into their suppliers' operations.

Simchi-Levi and Kaminsky (2007) discuss the importance of value stream mapping. They were keen to point out the need for firms to map their process so that they can capture their current value stream. The idea they had advanced was to ensure that cells within a firm would work together to create a future value stream in their business process. Their idea could be seen from the need for the organization to establish an efficient information flow that would, in turn, establish an information pull driven by the end customer demand (Danford, 2007). The DFS, for instance, use of technology such as the Galileo web-based applications, has provided a crucial means for DFS adoption of a virtual warehouse. The introduction of Umoja, more recently, has added different layers of applications that are increasingly enhancing the logistics and physical distribution operations of the DFS. Umoja is customized Enterprise Resource Planning software that is deployed for use by the DFS, and it has allowed the UNSC to manage the physical distribution of inventories and surplus stock across all DFS Field and Special Political Missions.

According to Lambert (2012), operating a lean warehouse would imply an elimination of nonvalue added steps as well as eliminating waste in the warehousing storage processes. A typical warehousing operation involves receiving and inspections, putting away commodities or storing commodities after the receiving and inspection operations, processing customer request through a picking and packing operations and lastly, distribution operations (Harland, 2012). Lean concepts in transportation as suggested by Cooper (2000), includes a carrier programs, improving transportation operations that encompass an administrative process and an automated functions. This movement mode can be designed to have an optimized mode selection and pooling orders. It would also have combined multi-stop truckloads, as well as a cross docking and right sizing equipment. Another aspect of this movement mode includes import/export transportation processes and inbound transportation operations as well as backhaul operations. A critical factor that would ensure that any organization can accomplish the concepts would include value stream mapping (VSM), the creation of a process flow, the reduction or eventual elimination in any processes that are considered waste, and eliminating non-value-added activities through pull methods (Danford, 2007). His findings are perhaps useful when we consider a functioning Transport Movement Integration and Cargo Coordination (TMICC) Unit at the RSCE. The TMICC concept is designed to provide common means of transportation with shared cost between field missions in the African Region. The TMICC concept has been able to manage what was once a complex optimization problem and with the sharing of costs, there has been saving and a reduction in duplicate contracts for the same service.

According to Lambert (2012), if the customer can fully understand their needs and can specify meaningfully these needs, it can be said that they are lean clients. These are customers that are said to value speed and flexibility in any processes. They expect high levels of delivery performance as well as high quality in product and services (Danford, 2007). These types of customers are interested in a partnership that is established by an effective relationship which always seeks methods of continuous performance improvement in a whole process that reduces costs. Customers are interested in the value that constitutes offerings, but also, that determines their value as measured by quality and customer satisfaction (Simchi-Levi, Kaminsky, \& SimchiLevi, 2003). The customer can also measure the products or services as a value purchase from and the satisfaction they gain from the use or through their interactions (FAO, 2007). 
According to Simchi-Levi, Kaminsky and Simchi-Levi (2003), literature is also useful in describing customer value. They had used key supply chain management issues to provide an illustration of the issues and strategies that can be deployed to achieve a globally optimized supply chain management system or an uncertainty in the supply chain management system, or both. Their work was useful for discussing key aspects of the DFS logistics and physical distribution systems and similar factors are applicable.

\subsubsection{Challenges of Implementing Lean Strategies}

Lean techniques have shown potentials to increase the magnitude of business process efficiency; reduce any fluctuation in organization's performance and increase improvement efforts and a commitment to reduced none value-added activities. The concepts highlight the significance of lean strategies. The use of lean techniques approach can provide integrated solutions that improve an organization's operational efficiencies. Lean solutions reflect improvements in business-level performance and process measurement. Ultimately, there is an assumption of an end state where process metrics is transformed into a process review system that allows managers to develop their organization's strategy and tactical tasks. However, implementation of lean strategies is often viewed as an explicit challenging goal (Simone \& Kleiner, 2004).

The use of lean strategies faces challenges since the technique itself, is a whole philosophy and not just a few sets of activities driven by some tools or techniques. These techniques, however, do have the potential to yield some benefits, when the gains that are obtained, come from the way the organization operations changes. These gains are achievable when the organization adopts lean techniques as a system through which the entire organization business culture changes - from the level of top management, down to the organization operatives. Additionally, the concept of lean thinking is not learned from reading a textbook. Lean techniques might be explained in textbooks. However, the need for personal guidance in the application of lean techniques is often necessary and is required to identify and implement the best lean practices from organizations that are useful for other organization operations. It is achievable when we understand the fundamental principles of lean philosophy and not just their tools and techniques. One of the barriers to understanding the lean thinking has been the lack of educators and consultants who can provide the require support when using real life examples of the application of lean techniques (Simone \& Kleiner, 2004).

Another challenges experienced is the lack of supply chain integration and collaboration. It is especially so, with trade, marketing, distribution teams, the lack of inventory review and the lack of supplier's engagements; all challenged lean implementation (Simone \& Kleiner, 2004). Failure to empower people is also a major problem in the application of lean strategies. Training people so that they adopt the improvement concept should not be seen as the only way by which people within the organization can be empowered. They had to be a part of the process that foster improvement. They had to be the people who are fully engaged in the processes that find a solution to problems associated with business process efficiency. They are the same people who had been part of the problem and it was good that they be part of solving the problem. It also meant that people would be allowed to work through a well-structured 'Plan-Do-Check-Act' approach that would be guided and supported by the organization. With time, they would be able to adopt to new improvement techniques as part of their day-to-day work. However, if there were a lack of understanding and a clear ownership of the change process, visibility of the desired activities would elude any organization. Of course, the statement lend credence to the views of 
Simone and Kleiner (2004) and they are credited to providing an explanation to the issues related to the recognition output constraints and management, as well as capacity planning, which had poses a challenge to the implementation of lean techniques.

A study carried out by Bolo (2009) on a number of selected strategic variables were based on firms supply chain management performance, with the study site been Kenya and case study been manufacturing companies. Bolo (2009) suggested that both small and large manufacturers had experienced lean challenges that were due to inadequate technology and the lack of management support in achieving lean objectives. Another study done by Wainaina (2009), had a look at supply chain management best practices that were practice in large private manufacturing firms in Kenya. The study had identified lean enterprises challenges that were characterized by factors such as insufficient monitoring and control, as well as insufficient oversight of the suppliers' delivery time. There was also the lack of vendors' engagement observed during the study as well as the lack of supply chain integration and collaboration. These observations highlighted by Wainaina (2009) typically experienced market trading and distribution. The impact had been the lack of close inventory review and no periodical checks. There was also a lack of clear line responsibility internally in most large firm supply chain management, and equally, a lack of understanding and visibility in the desired marketing activities. Having cited these negative factors that hinder improvements, she when on to suggest that there was a growing lack of understanding and recognition production constraints and capacity management planning that had serious implication for any lean strategy. These observations can be seen from the challenges that the DFS continue to face when you consider the fact that acceptance in transforming the business processes of the organization have not taken hold after five (05) years of the adoption of the GFSS.

\subsection{RESEARCH METHODOLOGY}

The study employed a qualitative research design. The study targeted all the senior managers at Director Levels at the GSC and the RSC and all the senior operational staff from supply chain and service delivery pillars in three (03) large Field Missions. These field missions are namely United Nations Stabilization Mission in Congo (MONUSCO); United Nations Mission in South Sudan (UNMISS); and the United Nations Support Office for AMISOM (UNSOA). This study used purposive sampling technique. The researcher purposively sampled fifteen (15) personnel; with three (03) participants each from the GSC, RSC, and three (03) participants each from the three (03) Field Mission. Primary data was obtained from the original sources using questionnaires and interview.

\subsection{RESULTS AND DISCUSSIONS}

\subsection{Response Rate of the Respondents}

The number of questionnaires that were administered was 10. All the sampled respondents participated fully which helped to achieve maximum response.

\subsection{Demographic Characteristics of the Respondents}

This section consists of information that describes basic characteristics of the respondents such as gender of the respondents, position in the organization, the level of education of the respondents and experience in the organization. 
International Journal of Supply Chain and Logistics

ISSN 2520-3983 (Online)

Vol.1, Issue 1, pp 28 - 54, 2017

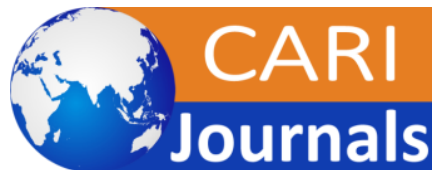

www.carijournals.org

Table 1: Demographic Characteristics of the Respondents

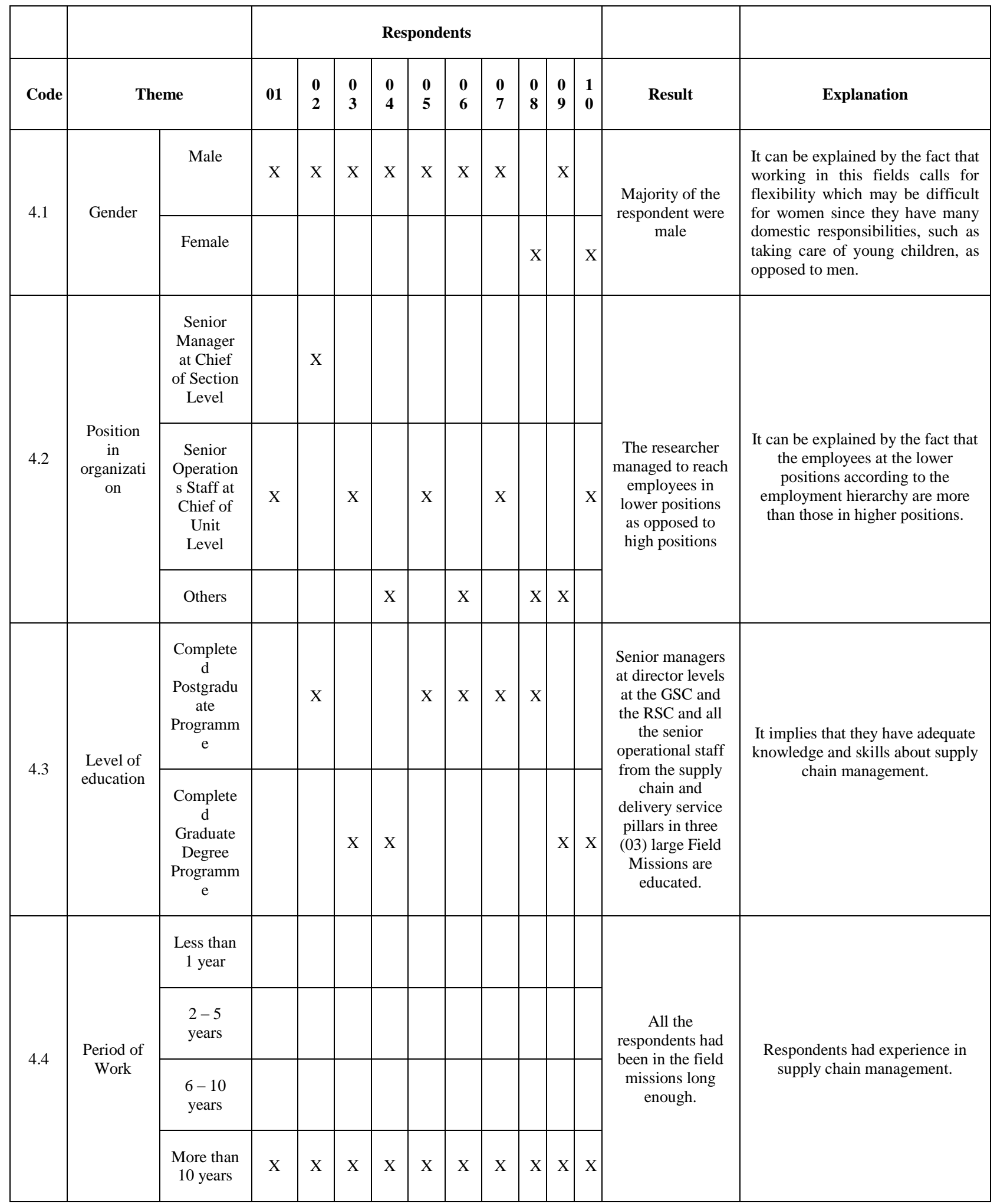


In the DFS, the demographic makeup of the current workforce is a mixed of old and young talents. Essentially, some challenges would be associated with implementing changes to better the operations of the DFS when to consider the demographic of the DFS. An investigation into the demographic would consider perception and mindset and resistance to change. Conquering that mindset of older and more experienced staff into accepting the current changes that involve the use of Lean strategies would be a major challenge. Over the last five (05) years, that is trends that since to suggest an emergence of a higher acceptance level of the changes that are taken place despite the clashes related to a mindset based on the demographic factors. The use of lean strategies have provided evidence of gains or failures in improving the DFS operations and have resulted in the recognition that there is a need for the strategy to work so that it does not harm performance quality and member states contributions. Table 1 shows the demographic characteristics of the respondents.

\subsection{Lean Strategies Used By DFS to Manage its Operation}

In respect to the lean strategies used by DFS to manage its operations. The study used a questionnaire and a key informant interview guide. The key informant respondents indicated that in the context of GFSS, lean stands for improved efficiency, economies of scales in using resources while ensuring improved service delivery to customers. Also, it implies timely service delivery. These results concur with those of Schonbergerm (2007) who asserts that organizations around the world have adopted lean philosophy to improve performances and to date, the strategy remains efficient in the face of increasing demand from customers for an improved quality of products and services business organization provide. Lean strategies are perhaps the most widely used management tools that organizations deploy when attempting to improve their business process efficiency and service quality (Schweikhart \& Dembe, 2009; Pool, Wijngaard, and van der Zee, 2011; Brun, 2011); Droste, 2007; Shah \& Ward, 2003). Jayaram, Das and Nicolae (2010) and Scherre-Rathje et al. (2009) had articulated Lean techniques based on the Toyota Way of waste elimination; achieving continuous performance improvement (CPI) by significantly reducing process time and achieving customer satisfactions. The description provided by Vienazindiene and Ciarniene (2013), suggested that lean strategies not be only about eliminating waste but also creating value for customers.

\subsubsection{Experience Using Lean Strategies}

Using the questionnaire the respondents were asked to indicate if they had any experience using lean strategies in designing an organization comprehensive logistics and physical distribution operations. Results are presented in the table 2.

Table 2: Experience Using Lean Strategies

\begin{tabular}{|c|c|c|c|c|c|c|c|c|c|c|c|c|}
\hline & \multicolumn{7}{|c|}{ Respondents } & \\
\hline Code & Theme & $\mathbf{0 1}$ & $\mathbf{0 2}$ & $\mathbf{0 3}$ & $\mathbf{0 4}$ & $\mathbf{0 5}$ & $\mathbf{0 6}$ & $\mathbf{0 7}$ & $\mathbf{0 8}$ & $\mathbf{0 9}$ & $\mathbf{1 0}$ & Result \\
\hline 4.5 & $\begin{array}{c}\text { Experience using } \\
\text { lean strategies }\end{array}$ & $\mathrm{X}$ & $\mathrm{X}$ & $\mathrm{X}$ & & $\mathrm{X}$ & $\mathrm{X}$ & $\mathrm{X}$ & $\mathrm{X}$ & & & $\begin{array}{c}\text { Most of the respondents } \\
\text { indicated that they had } \\
\text { experience using lean } \\
\text { strategies }\end{array}$ \\
\hline
\end{tabular}




\subsubsection{Emphasis of Mission Lean Strategy}

The key informant respondents were asked to indicate what mission lean strategy emphasizes, individuality rather than as part of the DFS. Some of the respondents indicated that in the GSC the mission lean strategy emphasized on the elimination of waste and duplication through centralization of operation (warehousing, maintenance, budgeting and procurement). It is supported by Shah and Ward (2003) who argues that a lean strategy must be designed to produce outputs that match the pace of the demand from customers while ensuring the elimination any form of waste. Other respondents indicated that the mission lean strategies emphasized on rapid troop deployment in remote and dangerous areas.

\subsubsection{Change Management}

The key informant respondents were also asked to indicate what section/department within their organization was responsible for the change management. Some of the respondents indicated that the GFSS team at UNHQ was in charge of change management. The other respondents also indicated that GFSS was in charge of change management in the field mission. The respondents also indicated that all the stakeholders were involved in change management whereby they took up the responsibility of ensuring a good flow of information to the various departments.

\subsubsection{Lean Transformation Leadership (LTL) in Your Organization}

The respondents were also asked to indicate who is responsible for formulating their organization lean leadership strategy (locally/HQ). All the respondents indicated that the HQ was responsible for formulating their lean organization strategy which was applied locally. They also indicated that they were prepared to be responsible for the organizational developing or implement your lean organization strategy through training (lean and six-sigma) and project work.

Further, the respondents indicated that they are held accountable/responsible for the successful management of specific aspects of the lean organization program through directive and performance evaluation. All the respondents also agreed to the statement that success in the United Nations lies in a better working relationship between good staff and a good supervisor. This attribute is paramount in achieving a Lean organization. They supported this by stating that teamwork, the unity of purpose is paramount to the successful implementation of the lean strategy. Finally, all the respondents indicated that the leadership strategies of their organization that allow for consensus building, a culture that encourages your employees to accept the organization business process re-engineering in their organization include stakeholder engagement, expectation, benefit and risk management and good communication. These findings can be supported by Lavassani and Kumar (2009) who highlight the significance of process improvement when creating a 'flow' and 'pull' system. In their findings, they were keen to stress that firms should start with radically re-engineering individual process steps when creating a 'flow' and 'pull' systems. Lean transformational leadership can help to create a 'flow' and 'pull' system. Pool, Wijngaard, and van der Zee (2011), findings also lend credence to Lean techniques as improvement tools that were useful in re-engineering any system. Such system had to be associated with a domain of knowledge that emerges from the organization refusal to accept waste. This claim can be supported by Wormack et al. (1990). They held the view that Lean rely significantly on the organization refusal to accept waste. 


\subsubsection{Prioritizing Lean Strategies}

The key informant respondents were also asked to indicate what their organization was doing to make the implementation of lean strategies a priority. The respondents indicated that some actions taken were only done when raised in audit observations. One respondent indicated that the organizations prioritized lean strategies through the RSC-E by enabling operations in more remote and dangerous environments to be move from the Field to the Service Center. It was achieved through prioritizing safety, security and welfare of personnel, and expanding shared services for non-location dependent functions. Another respondent indicated that they prioritized lean strategies through strengthening collaboration with Field Mission. It was achieved through prioritizing joint planning and deployment synchronization with Office of Military Affairs and Office of the Rule of Law and Security Institution Groups (ROLSIG), to ensure that new units become rapidly operational, enable more proactive, flexible and mobile operations.

The key informant from the RSC-E indicated that lean strategies had strengthened and improved quality of service delivery. It was achieved by delivering more consistent, higher quality services for clients, being careful of the limited resources by absorbing cost increases from existing budgets, finding creative solutions for clients, reducing fixed costs where possible, reviewing resources and finding productivity gains, and measuring performance rigorously. Top priority is for the RSCE - with full support of client missions and HQ - to deliver improved performance and customer satisfaction. Finally, the fifth respondent indicated that they prioritized lean strategy by ensuring corporate reforms work in the field. It was accomplished by improving supply chain management, restructuring mission support, expanding shared services and rolling out Umoja Extension 1. These findings can be supported by Péter (2012) who described the establishment of the UNSC as a strategic policy decision with significant importance for logistics and physical distribution in the DFS. The study found out that through the creation of the UNSC, the GSC for instance, had the ability to leverage its operational improvement strategy by effectively managing the DFS SCM system. His findings are useful, and they suggest an efficient management of the organization operations through two (02) pillars - supply chain management (SCM) and service delivery.

\subsubsection{Types of Lean Strategies}

The key informant respondents were asked to indicate what lean strategies are in place to ensure performance improvement at different job levels within their organization. The respondents indicated that their organizations have taken up various lean strategies. Some of them indicated that DFS has embarked on establishing a formal business performance and analysis entity as part of leveraging analytics and business intelligence in improving the performance of DFS. Another respondent indicated that their organization respond rapidly and flexibly to diverse demands. Another respondent also indicated that their organization ensure the highest standard of quality and client orientation. Further, the respondents also indicated that their organization has endeavored to enhance financial and strategic resourcing, adopted a human resources framework, taken up the shared services approach, supply chain management and modularization and new quality management approaches. These findings can be reinforced by Droste (2007) whose research results pointed to a cluster around lean strategies. He asserted that lean strategies improve the operational performance, assist achieving a high level of efficiency in product and service outputs. 


\subsubsection{Remedies for Organization Lean Strategies to Sustain Performance}

The key informant respondents were asked to indicate their thoughts on the remedies for their lean organization strategies to sustain performance. The respondents indicated that there was need to establish formal strategic plans to direct and align the work of the organization and supported by an objectives and data-driven performance monitoring, analysis, and reporting. They also indicated that there is a need for more efficient monitoring of all GA resolutions and audit recommendations. Other respondents indicated that the organization needs to monitor more closely the manner of compliance with the provisions of the memorandums of understanding. Also, the respondents indicated that their organizations ought to adopt change management strategy. DFS supply chain concept, E. Africa supply chain concept, and performance measurement system and align the GFSS strategy with Umoja and IPSAS implementations.

\subsection{Managerial Challenges}

\subsubsection{Experience Managerial Challenges}

Using the questionnaire, the respondents were asked to indicate whether they experienced managerial challenges in using lean techniques in designing a comprehensive characterization of the organization logistics and physical distribution system. All the respondents agreed that they experienced managerial challenges in using lean techniques in designing a comprehensive characterization of the organization logistics and physical distribution system. These confirm Simone and Kleiner (2004) assertion that the use of lean strategies faces challenges since the technique itself, is a whole philosophy and not just a few sets of activities driven by some tools or techniques.

\subsubsection{Types of Managerial Challenges}

The respondents were also asked to indicate the managerial challenges they experienced in using lean techniques in designing a comprehensive characterization of the organization logistics and physical distribution system. Results in Table 3 show an overview of the results.

Table 3: Type of Managerial Challenges

\begin{tabular}{|c|c|c|c|c|c|c|c|c|c|c|c|c|c|}
\hline & & \multicolumn{10}{|c|}{ Respondents } & & \multirow[b]{2}{*}{ Recommendation } \\
\hline Code & $\begin{array}{l}\text { Managerial } \\
\text { Challenges }\end{array}$ & 01 & 02 & 03 & 04 & 05 & 06 & 07 & 08 & 09 & 10 & Result & \\
\hline 4.6 & $\begin{array}{l}\text { Lack of supply } \\
\text { chain integration } \\
\text { and collaboration } \\
\text { internally within a } \\
\text { single entity (e.g. } \\
\text { UNSOS Sections). }\end{array}$ & $X$ & $X$ & $\mathrm{X}$ & & $\mathrm{X}$ & $\mathrm{X}$ & $\mathrm{X}$ & $X$ & & & $\begin{array}{l}\text { Supported } \\
\text { fully }\end{array}$ & Action required \\
\hline 4.7 & $\begin{array}{l}\text { Lack of periodic } \\
\text { physical inventory } \\
\text { review or physical } \\
\text { check of goods in } \\
\text { stock. }\end{array}$ & $\mathrm{X}$ & $X$ & $X$ & & X & & X & $X$ & & & $\begin{array}{l}\text { Supported } \\
\text { moderately }\end{array}$ & Action required \\
\hline 4.8 & $\begin{array}{l}\text { Lack of } \\
\text { engagement with } \\
\text { suppliers/vendors } \\
\text { in the logistics and } \\
\text { physical } \\
\text { distribution } \\
\text { operations as part }\end{array}$ & $\mathrm{X}$ & $X$ & $X$ & $\mathrm{X}$ & $X$ & $\mathrm{X}$ & $\mathrm{X}$ & $\mathrm{X}$ & & $\mathrm{X}$ & $\begin{array}{l}\text { Supported } \\
\text { fully }\end{array}$ & Action required \\
\hline
\end{tabular}


International Journal of Supply Chain and Logistics

ISSN 2520-3983 (Online)

Vol.1, Issue 1, pp 28 - 54, 2017

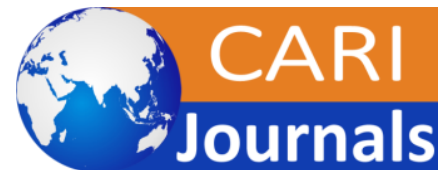

www.carijournals.org

\begin{tabular}{|c|c|c|c|c|c|c|c|c|c|c|c|c|c|}
\hline & $\begin{array}{l}\text { of the organization } \\
\text { supply chain } \\
\text { management. }\end{array}$ & & & & & & & & & & & & \\
\hline 4.9 & $\begin{array}{ll}\text { Lack of clear } \\
\text { responsibilities } \\
\text { within } \\
\text { organization } & \\
\text { logistics } & \text { and } \\
\text { physical } & \\
\text { distribution } & \\
\text { operations. } & \end{array}$ & $\mathrm{X}$ & $\mathrm{X}$ & $\mathrm{X}$ & & $\mathrm{X}$ & & $\mathrm{X}$ & $X$ & & $\mathrm{X}$ & $\begin{array}{l}\text { Supported } \\
\text { fully }\end{array}$ & Action required \\
\hline 4.10 & $\begin{array}{l}\text { Lack of } \\
\text { understanding of } \\
\text { lean concepts and a } \\
\text { lack of a visible } \\
\text { application of the } \\
\text { concepts to assist in } \\
\text { achieving the } \\
\text { organization desire } \\
\text { change program. }\end{array}$ & $\mathrm{X}$ & $\mathrm{X}$ & & & $\mathrm{X}$ & $\mathrm{X}$ & $\mathrm{X}$ & $\mathrm{X}$ & & & $\begin{array}{l}\text { Supported } \\
\text { moderately }\end{array}$ & Action required \\
\hline 4.11 & Lack of training. & $\mathrm{X}$ & $\mathrm{X}$ & $\mathrm{X}$ & & $X$ & $\mathrm{X}$ & $\mathrm{X}$ & $X$ & $\mathrm{X}$ & $\mathrm{X}$ & $\begin{array}{l}\text { Supported } \\
\text { fully }\end{array}$ & Action required \\
\hline 4.12 & $\begin{array}{l}\text { Lack of a clear } \\
\text { communication } \\
\text { plan for the } \\
\text { implementation of } \\
\text { lean strategies in } \\
\text { improving the } \\
\text { organization } \\
\text { logistics } \\
\text { physical and } \\
\text { distribution } \\
\text { operations. } \\
\end{array}$ & $\mathrm{X}$ & $\mathrm{X}$ & & $X$ & $\mathrm{X}$ & $\mathrm{X}$ & $\mathrm{X}$ & $\mathrm{X}$ & $\mathrm{X}$ & $\mathrm{X}$ & $\begin{array}{l}\text { Supported } \\
\text { fully }\end{array}$ & Action required \\
\hline 4.13 & $\begin{array}{l}\text { Lack of an } \\
\text { integrated } \\
\text { information } \\
\text { technological } \\
\text { system that fits the } \\
\text { application of lean } \\
\text { concept to re- } \\
\text { engineering the } \\
\text { organization } \\
\text { logistics } \\
\text { physical and } \\
\text { distribution } \\
\text { operations. }\end{array}$ & $\mathrm{X}$ & $X$ & $X$ & & $X$ & $X$ & & $X$ & & & $\begin{array}{l}\text { Supported } \\
\text { moderately }\end{array}$ & Action required \\
\hline 4.14 & $\begin{array}{l}\text { Lack of use of } \\
\text { technology to } \\
\text { monitor and control } \\
\text { the delivery time of } \\
\text { goods by } \\
\text { suppliers/vendors } \\
\text { so that the } \\
\text { organization is able } \\
\text { to fulfill end } \\
\text { customer } \\
\text { requirement just in } \\
\text { time. }\end{array}$ & $\mathrm{X}$ & $X$ & $X$ & & $X$ & $\mathrm{X}$ & $\mathrm{X}$ & & & & $\begin{array}{l}\text { Supported } \\
\text { moderately }\end{array}$ & Action required \\
\hline 4.15 & $\begin{array}{l}\text { Lack of an } \\
\text { effective supplier } \\
\text { engagement as part } \\
\text { of managing the } \\
\text { organization global } \\
\text { system contract, } \\
\text { core to the }\end{array}$ & $\mathrm{X}$ & & $\mathrm{X}$ & & & $\mathrm{X}$ & $\mathrm{X}$ & & & & $\begin{array}{c}\text { Supported } \\
\text { partially }\end{array}$ & Action required \\
\hline
\end{tabular}




\begin{tabular}{|c|c|c|c|c|c|c|c|c|c|c|c|c|}
\hline & $\begin{array}{l}\text { organization supply } \\
\text { chain management. }\end{array}$ & & & & & & & & & & & \\
\hline 4.16 & $\begin{array}{l}\text { Lack of adequate } \\
\text { audit of the } \\
\text { periodic physical } \\
\text { inventory review } \\
\text { by DFS Field } \\
\text { Mission and the } \\
\text { implementation of } \\
\text { audit } \\
\text { recommendations } \\
\text { for improving the } \\
\text { organization } \\
\text { logistics and } \\
\text { physical } \\
\text { distribution } \\
\text { operations. }\end{array}$ & $X$ & & $\mathrm{X}$ & & & $\mathrm{X}$ & & & $\mathrm{X}$ & $\begin{array}{l}\text { Supported } \\
\text { partially }\end{array}$ & Action required \\
\hline 4.17 & $\begin{array}{lr}\text { Lack } & \text { of } \\
\text { understanding and } \\
\text { recognition of the } \\
\text { internal constraints } \\
\text { in managing the } \\
\text { organization } \\
\text { logistics } \\
\text { physical and } \\
\text { distribution } \\
\text { operations. }\end{array}$ & & $\mathrm{X}$ & & $\mathrm{X}$ & & $\mathrm{X}$ & & $\mathrm{X}$ & & $\begin{array}{l}\text { Supported } \\
\text { partially }\end{array}$ & Action required \\
\hline 4.18 & $\begin{array}{l}\text { Lack of an efficient } \\
\text { and effective } \\
\text { capacity planning } \\
\text { of the organization } \\
\text { logistics and } \\
\text { physical } \\
\text { distribution } \\
\text { operations to fulfill } \\
\text { the complex } \\
\text { mandates of field } \\
\text { missions. }\end{array}$ & $\mathrm{X}$ & $\mathrm{X}$ & $\mathrm{X}$ & & $\mathrm{X}$ & & $\mathrm{X}$ & & $\mathrm{X}$ & $\begin{array}{l}\text { Supported } \\
\text { moderately }\end{array}$ & Action required \\
\hline
\end{tabular}

The key informant respondents were also asked to indicate what managerial challenges they were facing in using lean techniques to design a comprehensive characterization of the organization logistics and physical distribution system. The respondents indicated that they experienced a lack of understanding of the complexity of supply chain at the senior leadership level whereby most initiatives are tainted with personal agenda as a consequent the biggest hurdle to overcome is gaining enthusiasm and trust of the staff. They also indicated that there is a high risk of asset waste and loss due to assets remaining in stock for over one year without use. Further, they indicated that there are weaknesses in the management of construction or "selfconstructed" projects; and weaknesses in the restructuring of the department of peacekeeping operations. Various authors (Simone and Kleiner, 2004; Bolo, 2009; Wainaina 2009) support these findings in their work as they have stated there exists challenges in application and implementation of lean strategies.

\subsubsection{Challenges in Implementing Lean Strategies}

The key informant respondents were asked to outline what problems they faced in their organization when implementing lean strategies to improve their operations. In response, the respondents indicated that they experienced various problems such as lack of trust, lack of clear objectives, no baseline established to measure benefits against, no formal project management to ensure success, concurrent changes with IPSAS and Umoja and lack of qualified staff. These 
findings are supported by Simone and Kleiner, (2004) who asserted that lack of clear responsibility, understanding and visibility of the desired work activities, recognition of work constraints and management, as well as capacity planning pose challenges to lean implementation.

\subsubsection{Effect of Operational Challenges}

The respondents were asked to indicate the effect of the operational challenges on the Department of field services operations across field missions. Results in Table 4.4 show an overview of the results. These findings are consistent with Marvel and Standridge (2009) who argued that when lean strategies are applied incorrectly by the organization, the result would be an increase in the organization's inefficient use of resources; amounting to a reduced employee confidence in the lean approach.

Table 4: Effect of Operational Challenges

\begin{tabular}{|c|c|c|c|c|c|c|c|c|c|c|c|c|c|}
\hline & & \multicolumn{10}{|c|}{ Respondents } & & \multirow[b]{2}{*}{ Recommendation } \\
\hline Code & $\begin{array}{l}\text { Effect of } \\
\text { Operational } \\
\text { Challenges }\end{array}$ & 01 & 02 & 03 & 04 & 05 & 06 & 07 & 08 & 09 & 10 & Result & \\
\hline 4.19 & $\begin{array}{l}\text { Extremely } \\
\text { increases } \\
\text { customer } \\
\text { satisfaction. }\end{array}$ & $\mathrm{X}$ & & $\mathrm{X}$ & & $\mathrm{X}$ & & & $\mathrm{X}$ & & & $\begin{array}{c}\text { Supported } \\
\text { partially }\end{array}$ & Action required \\
\hline 4.20 & $\begin{array}{l}\text { Increases } \\
\text { operational cost } \\
\text { to the } \\
\text { organization. }\end{array}$ & $\mathrm{X}$ & $\mathrm{X}$ & $\mathrm{X}$ & & $\mathrm{X}$ & $\mathrm{X}$ & $\mathrm{X}$ & $\mathrm{X}$ & & & $\begin{array}{l}\text { Supported } \\
\text { moderately }\end{array}$ & Action required \\
\hline 4.21 & $\begin{array}{l}\text { Increase } \\
\text { supplier leads } \\
\text { time of goods } \\
\text { with implication } \\
\text { for poor service } \\
\text { delivery in the } \\
\text { field. }\end{array}$ & $\mathrm{X}$ & $\mathrm{X}$ & & $\mathrm{X}$ & $\mathrm{X}$ & & $\mathrm{X}$ & $\mathrm{X}$ & & $\mathrm{X}$ & $\begin{array}{l}\text { Supported } \\
\text { moderately }\end{array}$ & Action required \\
\hline 4.22 & $\begin{array}{l}\text { Reduce the } \\
\text { service quality } \\
\text { to end customer } \\
\text { through a poorly } \\
\text { managed } \\
\text { logistics and } \\
\text { physical } \\
\text { distribution } \\
\text { operations. }\end{array}$ & $\mathrm{X}$ & & $\mathrm{X}$ & & & & & & & & $\begin{array}{c}\text { Not } \\
\text { supported }\end{array}$ & Action required \\
\hline
\end{tabular}

\subsection{SUMMARY, CONCLUSIONS AND RECOMMENDATIONS}

\subsection{Summary of Findings}

\subsubsection{Lean Strategies Used By DFS to Manage its Operation}

The research achieved this objective by answering several questions. As a starting point, the research sought to find out if the respondents had any experience using lean strategies in designing an organization comprehensive logistics and physical distribution operations. The results revealed that the organizations researched did have experience using lean strategies in designing a comprehensive logistics and physical distribution operations. The research also 
sought to find out what lean strategies were emphasized by the UN Service Centers and Field Missions. The results revealed that Field Missions had adopted individuality approach with a skew but as part of the DFS Global Field Support Strategy (GFSS). For instance, the results obtained from the interview showed that in GSC, the lean strategies place emphasis on the elimination of waste and duplication buying through the centralization of operation.

The research also sought to determine what section/department within the organization was responsible for the change management. The results revealed that in the UNHQ, the GFSS team was in charge of change management. The results also showed that GSC was central to ensuring that the GFSS was implemented across Field Missions. Furthermore, the research sought to find out who was responsible for formulating their organization lean leadership strategy (locally/HQ). The results revealed that the HQ was responsible for formulating their lean strategies which were applied locally. The research also sought to find out whether the respondents were held accountable/responsible for the successful management of specific aspects of their organization lean program. The results revealed that they were responsible for directive and performance evaluation. The research also sought to find out what the organization was doing to make the implementation of lean strategies a priority. Findings from the research revealed that actions were taken by all five (05) organizations, only when audit observations were raised by the Office of Internal Oversight Services (OIOS). For instance, audit observations revealed that services conducted in the field could be moved to the RSC-E. As a result, the DFS prioritized lean strategies that enable operations in more remote and dangerous environments to be moved to the RSC-E. Lean strategies were strengthened by improving the quality of service delivery and prioritized by ensuring corporate reforms work in the field.

The research also sought to find out what lean strategies are in place to ensure performance improvement at different job levels within their organization. The results revealed that the DFS had embarked on establishing a formal business performance and analysis entity as part of leveraging analytics and business intelligence in improving the performance of the organization and its abilities to respond rapidly and flexibly to diverse demands. The approach has ensured the highest standard of quality and client orientation, enhancing financial and strategic resourcing, adopting a human resources framework, taking up the shared services approach, supply chain management and modularization and new quality management approaches.

\subsubsection{Managerial Challenges}

The research achieved this objective by seeking answers to several questions. To start with the author sought to find out whether the respondents experienced managerial challenges. The results revealed that they indeed experienced various managerial challenges. The research also sought to determine whether DFS faces challenges implementing lean strategies. The results revealed that DFS did face various challenges in the implementation of lean strategies. Further, the author sought to find out the effect of the operational difficulties on the Department of field services operations across field missions. The results revealed that the presence of these challenges resulted in reduced customer satisfaction, increased supplier lead time and increased operational costs.

\subsection{Conclusions and Recommendations}

Use of lean strategies at DFS has not yet realized its full potential. It can be explained by the fact that the implementation process is still underway, and the DFS management team is facing 
various challenges. Some of these challenges are caused by resistance to change from the staff and the logistics involved in the implementation process. In a bid to establish what measures can be put in place so as to improve the operations of DFS, the author has asked questions on remedies/solutions to better performance of DFS in different sections of the questionnaire and the key informant interview guide. From the results in the chapters above and literature, it is possible to make the following recommendations to the management of DFS.

i. Strategic plans - there is need to establish formal strategic plans to direct and align the work of the organization and supported by objectives and data-driven performance monitoring, analysis, and reporting.

ii. Monitoring and evaluation there is a need for more efficient monitoring of all GA resolutions and audit recommendations. The organization needs to monitor the manner of compliance with the provisions of the memorandums of understanding.

iii. Incorporating balanced performance knowledge in the integration of people, processes, technology and customer service level to ensure customer satisfaction while proving economy and effectiveness in dedicated resources. Shared and remote services help optimize resources, minimize the number of support staff in danger zones, balance workload and ensure business continuity.

iv. DFS should foster a continuous performance improvement mindset among staffs through planning, doing, checking and taking corrective actions on a balanced scorecard that integrates and aligns staff motivation and interest to the objectives of the organization. Also, objective and fair work plan and performance management are an ingredient to foster continuous improvement.

v. A global distribution center is required either at GSC or the RSC where FMs can pull goods from. The center should be linked to vendors ERP system to enable vendors visibility access to our inventory so that production could be automatically ramped up based on future demand. Also, the policy of having a separate freight forwarder of goods should be discontinued as it adds too much time to a financial system that is not perpetual, but fixed time, transactions cycle is limited to the financial year.

vi. $\quad$ Align the GFSS strategy with Umoja and IPSAS implementations.

vii. Integration, data sharing, successfully implemented ERP and more qualified staff.

viii. There is a need for change since inventories and acquisitions are still not fully managed in a comprehensive and holistic manner. Missions are still managing acquisitions and inventories in isolations.

ix. Better systems contracts should be put in place for better delivery lead times so as to meet concurrent demand [which is outside of GSC purview].

x. There is a need for greater central support and clear policies from the headquarters.

\subsection{Limitations of the Study}

The study used a population of fifteen (15) respondents from five different organizations namely GSC, RSC and the three (03) field missions (UNMISS, MONUSCO, and UNSOA). It posed a limitation trying to make a comparison of the respondents' feedback because the different stations/centers had different experiences using lean strategies. Further, the results of this study are very unique to UN (DFS operations) and thus it would be difficult to apply them in another organization. Another limitation could emanate from the issue of confidentiality whereby the respondents would give biased information for the fear of victimization. Despite these 
weaknesses, the research results are considered valid and reliable as appropriate measures have been applied to ensure validity and reliability as described in more detail in chapter three above.

\subsection{Suggestions for Future Research}

Further study should be conducted on the influence of staff demographic characteristics on the implementation of lean strategies in DFS. A similar study can also be carried out in different NGO. It would assist in comparing the lean strategies that influence performance/operation in the various organizations.

\section{REFERENCES}

Aldowaisan, T. A., \& Gaafar, L. K. (1999). Business process reengineering: an approach for process mapping. Omega, 27(5), 515-24.

Bisson, B., \& Folk, V. (2000). Case study: How to do business process improvement. The Journal of Quality and Participation, 23(1), 58-63.

Bolo, A. (2009). Selected strategy variables on firm's performance of supply chain management in large private manufacturing firms in Kenya. (Unpublished MBA Project, University of Nairobi).

Brun, A. (2011). Critical success factors of six sigma implementations in Italian companies. International Journal Production Economics, 131, 158-164.

Damelio, R. (1996). The basics of process mapping quality resources. New York, NY.

Danford, M. D. (2007). Middle management resists lean implementation, survey suggests.' Modern Machine Shop, 80(5), 1.

Droste, A. (2007). Lean thinking: Banish waste and create wealth in your corporation', Action Learning: Research and Practice, 4(1), 105-106.

Edgeman, R. L., \& Bigio, D. I. (2004). Six sigma in metaphor: Heresy or Holy Writ?' Quality Progress, 37(1), 6.

FAO, (2007). Agro-industrial supply chain management: Concepts and applications. AGSF Occasional Paper 17 Rome. 
Fiume, O. (2004). Lean at Wiremold: Beyond manufacturing, putting people front and center. Journal of Organizational Excellence, 23-32.

Fournier, V., \& Grey, C. (2000). At the critical moment: Conditions and prospects for critical management studies. Human Relations, 53(1): 7-32.

Grey, C., \& Willmott, H. (2005). Critical management studies. Oxford: University Press.

Gripsrud, G., Jahre, M., \& Persson, G. (2006). Supply chain management - back to the future?' International Journal of Physical Distribution \& Logistics Management, 36(8), 643-659.

Grover, V., \& Malhotra, M. K. (2003). Transaction cost framework in operations and supplychain management research: Theory and measurement. Journal of Operations Management, 21(4), 457-473.

Harland, C. M. (2012). Supply chain management, purchasing and supply management, logistics, vertical integration, materials management and supply chain dynamics. In: Slack, N (ed.) Blackwell Encyclopedic Dictionary of Operations Management. UK: Blackwell.

Hotho, S., \& Pollard. D. (2007). Management as negotiation at the interface: Moving beyond the critical-practice impasse. Organization, 14(4): 583-603.

Huang, S. H., Sheoran, S. K., \& Wang, G. (2004). A review and analysis of supply chain operations reference (SCOR) model. Supply Chain Management: An International Journal, 9(1).

Jayaram, J., Das, A., \& Nicolae, M. (2010). Looking beyond the obvious: Unraveling the Toyota Production System. International Journal of Production Economics, 128, 280-291.

Jusko, J. (2007). Accounting for lean tastes. Industry Week, 256(9), 3.

Kallrath, J., Maindl, T. I. (2006). Real optimization with SAP® APO. Springer ISBN 3-54022561-7. 
Kärkkäinen, M., Ala-Risku, T., \& Holmstrm, J. (2003). Increasing customer value and decreasing distribution costs with merge-in-transit. International Journal of Physical Distribution and Logistics Management, 33(2), 132-148.

Keitany, P., \& Riwo-Abudho, M. (2014). Effects of lean production on organizational performance: a case study of flour producing company in Kenya. Eur J Logistics Purchasing Supply Chain Mgmt, 2(2), 1-14.

Keller, P. J., \& Jacka, J. M. (1999). Process mapping. The Internal Auditor, 56(5), 60-4.

Kouvelis, P., Chambers, C, \& Wang, H. (2006). Supply chain management research and production and operations management: Review, trends and opportunities. Production and Operations Management, 15(3), 449-469.

Kumar, S., \& Phrommathed, P. (2006). Improving a manufacturing process by mapping and simulation of critical operations. Journal of Manufacturing Technology Management, 17(1), 104-132.

Lambert, D. M. (Eds) (2012). Supply chain management: Processes, partnerships, performance, ( $3^{\text {rd }}$ ed.). Supply Chain Management Institute, Sarasota, FL.

Larson, P. D., \& Halldorsson, A. (2004). Logistics versus supply chain management: An international survey. International Journal of Logistics: Research \& Application, 7(1), 17-31.

Lavassani, K., Movahedi, B., \& Kumar, V. (2009). Developments in theories of supply chain management: The case of $\mathrm{B} 2 \mathrm{~B}$ electronic marketplace adoption. The International Journal of Knowledge, Culture and Change Management, 9(6), 85-98.

Marvel, J. H., \& Standridge, C. R. (2009). Simulation-enhanced lean design process. Journal of Industrial Engineering and Management, 2, 90-113.

Mentzer, J. T. et al., (2001). Defining supply chain management. Journal of Business Logistics, $22(2), 1-25$. 
Movahedi, B., Lavassani, K., \& Kumar, V. (2009). Transition to B2B e-Marketplace enabled supply chain: Readiness assessment and success factors. The International Journal of Technology, Knowledge and Society, 5(3), 75-88.

Parker, M. (2002). Against management. Cambridge: Polity Press.

Péter, B. (2012). Overview of the United Nations Logistics Base/Global Services Center.' Available at:http://hadmernok.hu/2012_2_benicsak.pdf. [Assessed: 18 April 2014]

Pool, A., Wijngaard, J., \& van der Zee, D. (2011). Lean planning in the semi-process industry: A case study. International Journal of Production Economics, 131, 194-203.

Scherrer-Rathje, M., Boyle, T. A., \& Deflorin, P. (2009). Lean, take two! Reflections from the second attempt at lean implementation. Business Horizons, 52, 79-88.

Schonbergerm, R. J. (2007). Japanese production management: an evolution with mixed success. Journal of Operations Management, 25, 403-19.

Schweikhart, S. A., \& Dembe, A. E. (2009). The applicability of lean and six sigma techniques to clinical and translational research. Journal of Investigative Medicine, 57(7), 745-755.

Sealander, J., \& Cross, K. (1999). Process redesign: is it worth it? Management Accounting, 80(7), 40-44.

Shah, R., \& Ward, P. T. (2003). Lean manufacturing: Context, practice bundles, andperformance. Journal of Operations Management, 21, 129-149.

Shokri, A., Oglethorpe, D., \& Nabhani, F. (2014). Evaluating six sigma methodology to improve logistical measures of food distribution SMEs. Journal of Manufacturing Technology Management, 25(7), 998 - 1027.

Simchi-Levi, D., Kaminsky, P., \& Simchi-levi, E. (2007). Designing and managing the supply chain, Third edition, Mcgraw Hill. 
Vienazindiene, M., \& Ciarniene, R. (2013). Lean manufacturing implementation and process measurement. Economics and Management, 18(2).

Wainaina, G. (2009). Supply chain management best practices in large private manufacturing firms in Kenya. (Unpublished MBA project, University of Nairobi).

Wan, H., \& Chen, F. F. (2008). A leanness measure of manufacturing systems for quantifyingimpacts of lean initiatives. International Journal of Production Research, 46, 6567-6584.

Womack, M., \& Jones, N. (2009). Lean practices in organizations. Industrial Engineer, 39(40), 1.

Yavuz, A., \& Cengiz, D. (2015). Impact of competitive strategies and supply chain strategies on the firm performance under environmental uncertainties: Borsa Istanbul case in the manufacturing sector. International Journal of Economics, Commerce and Management, 2(1).

Zakuan, N., \& Mat-Saman, M. Z. (2009). Lean manufacturing concept: The main factor inimproving manufacturing performance-a case study. International Journal of Manufacturing Technology and Management, 17, 353-363. 